\title{
Using an Online Dictionary for Identifying the Meanings of Verb Phrases by Chinese EFL Learners
}

\author{
Lingling Li, Department of Literature and Communication, \\ City College of Dongguan University of Technology, Dongguan, \\ P.R. China (rowena_lee@126.com) \\ and \\ Hai Xu, Centre for Linguistics and Applied Linguistics, \\ Guangdong University of Foreign Studies, Guangzhou, P.R. China \\ (xuhai1101@gdufs.edu.cn)
}

\begin{abstract}
This article reports on the results of a study which investigated the use of an online dictionary by Chinese EFL learners in identifying the meanings of verb phrases. Thirty-two students with English as major subject participated in a meaning determination task with and without the help of the Macmillan English Dictionary Online (MEDO). Introspective and retrospective questionnaires were used to establish the participants' perception of the usefulness of the online dictionary, and how they used the online dictionary to search for their needed information. The results of the study show that learners improved in doing the task after consulting the online dictionary, but they also encountered some problems which led to incorrect choices. It is suggested that dictionary skills training should be provided, and improvements to online dictionaries should also be made.
\end{abstract}

Keywords: ONLINE DICTIONARY, MACMILLAN ENGLISH DICTIONARY ONLINE, VERB PHRASES, MEANING IDENTIFICATION, DICTIONARY USE, DICTIONARY SKILLS, ENTRY STRUCTURE AND INFORMATION

Opsomming: Die gebruik van 'n aanlyn woordeboek deur Chinese EVTleerders vir die identifisering van werkwoordelike frases. Hierdie artikel doen verslag oor die resultate van 'n studie waarin 'n aanlyn woordeboek deur Chinese EVT-leerders gebruik is in die identifisering van werkwoordelike frases. Twee en dertig studente met Engels as hoofvak het deelgeneem in 'n betekenisbepalingsopdrag met en sonder die hulp van die Macmillan English Dictionary Online (MEDO). Introspektiewe en retrospektiewe vraelyste is gebruik om die deelnemers se persepsie van die nuttigheid van die aanlyn woordeboek te bepaal, asook om te bepaal hoe hulle die aanlyn woordeboek gebruik het om te soek na die verlangde inligting. Die resultate van die studie toon dat leerders verbeter het in die voltooiing van die taak nadat hulle die aanlyn woordeboek geraadpleeg het, maar dat hulle ook sommige probleme teëgekom het wat gelei het tot verkeerde keuses. Daar word voorgestel dat opleiding in woordeboekvaardighede verskaf moet word en dat verbeterings aan aanlyn woordeboeke ook aangebring moet word.

Sleutelwoorde: AANLYN WOORDEBOEK, MACMILLAN ENGLISH DICTIONARY ONLINE, 
WERKWOORDELIKE FRASES, BETEKENISHERKENNING, WOORDEBOEKGEBRUIK, WOORDEBOEKVAARDIGHEDE, INSKRYWINGSTRUKTUUR EN -INLIGTING

\section{Introduction}

Sparked by technological advancements, electronic dictionaries (EDs) have developed rapidly in the last three decades. From the first human readable electronic dictionary (ED) available for the public in the late 1980s, EDs have been available on: CD-ROM, small hand-held calculator-type reference works (i.e. pocket ED), and online. De Schryver (2003: 146) defined EDs as 'collections of structured electronic data that can be accessed with multiple tools, enhanced with a wide range of functionalities, and used in various environments'.

Research shows that EDs are in many respects valuable. Compared with the bulkiness of paper dictionaries and slow retrieval, the increasing popularity of EDs can be attributed to better readability and their ease of use which makes the consultation process less time-consuming. The most innovative aspect of EDs is probably the retrieval system (Nesi 2000a: 839). It encourages exploratory browsing which results in a large number of words looked up. It is believed that looking up more words might be helpful in word acquisition (Komuro et al. 2006). However, some researchers doubt the efficiency of EDs. Laufer and Hill (2000: 72) found that 'the number of times the word is looked up during a learning session bears almost no relation to its retention'. Hulstijn and Laufer (2001) further point out that deeper and more elaborate processing resulted in better word retention. There is a 'possibility that the most easily extracted information may require least thought, and be soonest forgotten' (Nesi 2000a: 844).

By investigating the usefulness of paper and CD-ROM versions of the Oxford Advanced Learner's Dictionary of Current English (5th edition), Nesi (2000b) concluded that there were no significant differences in comprehension scores between the two dictionary formats. Studies which investigated the use of hand-held devices reveal a complicated picture concerning the efficiency of EDs. Osaki et al. (2003) observed that compared with the paper dictionary use group, the portable ED consultation group performed much better in choosing the appropriate meaning of underlined target words, and gained better reading comprehension scores. Chen (2010) claimed that portable EDs could be as effective as paper dictionaries for new word acquisition for EFL learners. In stark contrast to the previous findings, some results suggest that the use of portable EDs contributed little to reading comprehension (Koyama and Takeuchi 2007), and compared with paper dictionaries, no statistically significant differences in reading comprehension scores could be observed (Kobayashi 2007).

In addition to CD-ROM and hand-held devices, researchers also began to show interests in online dictionaries. Due to the rapid development of the Internet, smart phones and iPads, ways of obtaining information have been diversified. With the easy and widespread access to the Internet, dictionary 
users can consult online dictionaries by hovering the mouse over a word on computer screens, or clicking on their smart phones and iPads wherever they go. Nearly all major traditional dictionaries have provided online versions with lexicographic information which can be as useful as their traditional hard copies (Li 2005: 16). Some publishers even go far beyond. Macmillan English Dictionary, one of the 'Big Six', has ceased the publication of paper dictionaries in 2013 and decided in favour of an online version only. Together with the multi-functions provided by online dictionaries, dictionary users can learn more about the latest revisions and new words as editors can update entry information every few months.

The advent of online dictionaries has greatly influenced users' preferences and patterns of dictionary use. In Dziemianko (2010), which concerns the paper and online versions of a monolingual dictionary, the online dictionary was found to be more useful in dealing with both receptive and productive tasks. Lew and Tokarek (2010) also examined the efficiency of entry menus in bilingual dictionaries in electronic format, but it is noted that the online dictionary used in their study was an experimental rather than an authentic one. It deserves further enquiry how useful an authentic online dictionary is for users and what problems they may encounter during their online dictionary consultation.

This study focuses on how users look up verb phrases in an authentic online dictionary. Verb phrases consist of a verb and one or two additional elements (generally called particles). They constitute a syntactic or lexical unit functioning as a whole like a single lexical verb, and they have to be acquired, stored and retrieved from memory as a holistic unit (Wray and Perkins 2000). They can be viewed as a type of formulaic sequence (Wray 2002). It is evident that the verb phrase is an important element of language learning and usage. Normal discourse, both written and spoken, contains a large percentage of verb phrases, but they are especially problematic for EFL learners (Howarth 1996; Nesselhauf 2005). The meanings of many verb phrases can hardly be decoded literally but have to be considered as a whole. One single verb can connect with several different particles to form different verb phrases with totally different meanings, and EFL learners often get confused. Moreover, the polysemy of many verb phrases confounds EFL learners. It is hard for them to know all the meanings of a polysemous verb phrase, and they may not have the ability to distinguish the subtle nuances of its many meanings, and mistakenly perceive the dominant meaning as the only meaning when they put it into practical use.

Compared with paper dictionaries that mainly organize entries around a single word, online dictionaries allow users to access multi-words by consulting more than one component of a multi-word (Lew 2012: 349-351). Thus, users can search for a certain verb phrase as a whole to identify its meaning. Furthermore, online dictionaries provide a search engine which links to other relevant information. Nevertheless, when faced with a lexical request, an online dictionary is rather less helpful (Lew and De Schryver 2014: 349). While search- 
ing polysemous entries, users themselves have to decide which sense is relevant in a particular context. It is therefore worthwhile to examine how EFL learners look up the meanings of polysemous verb phrases in an online dictionary, and what the problems they may have in choosing one sense over the others according to a certain context.

\section{Research questions}

The present study addresses the following questions:

(1) How useful is an online dictionary to determine the meaning of verb phrases?

(2) Do Chinese EFL learners perceive Macmillan English Dictionary Online as useful?

(3) What are the general problems Chinese EFL learners encounter in consulting an online dictionary?

\section{Participants}

One hundred and seven students with English as major subject at a local university in China took the Oxford Quick Placement Test in thirty minutes, and their scores were marked. Thirty-two students who scored between 30 and 39 were regarded as lower intermediates, and chosen as the participants. The implementation of the Oxford Quick Placement Test was to make sure that the participants were at the same English proficiency level. There were 7 males and 25 females, and their ages ranged from 18 to 20 years. Although advanced learners are considered to be those who often use a dictionary for self-learning purposes (Chan 2005), few studies focus on lower intermediate students. The results of studies on advanced learners may not be applicable to lower intermediates. Thus their dictionary usage should be examined.

\section{Instruments}

\subsection{Meaning determination task of verb phrases}

Twenty-six polysemous verb phrases were chosen, and were piloted with 33 students who were excluded from those 107 students. All the verbs in these phrases were simple words familiar to the learners, but the phrases as a whole might have been familiar or unfamiliar to them. The testing material was adapted from http://www.usingenglish.com/reference/phrasal-verbs/. These students had to determine the most appropriate meaning of an underlined verb phrase in each sentence by choosing the correct answer from a list of four choices without consulting dictionaries. The ten verb phrases with the highest 
error rate (between $81.82 \%$ and $54.55 \%$ ) were collected as the target phrases. The following is one example of the target verb phrases (see the Appendix 1 for a complete list).

(1) He had to break down their opposition to his ideas.

A. separate into parts

B. stop working

C. remove a barrier or obstacle

D. end negotiations unsuccessfully

The meaning determination task consisted of two parts. The first part examined the participants' prior knowledge of the target verb phrases, and the second part investigated how they used the online dictionary to help them determine the meanings of the target phrases.

\subsection{Questionnaires}

One introspective questionnaire and one retrospective questionnaire were adopted in this research. The introspective questionnaire aimed at eliciting participants' instant and detailed feedback on how they used a certain dictionary entry to help them determine the meaning of a verb phrase (Chan 2012), and the retrospective questionnaire aimed at figuring out the participants' overall evaluation of the usefulness of the online dictionary and its different elements in the meaning determination task (ibid.). Chan $(2012,2013)$ used her instant introspective questionnaire and retrospective questionnaire to investigate the participants' thinking processes of how they determined the meanings of familiar English words used in less familiar contexts. Since the results of both studies identified different kinds of consultation problems, the questionnaires can be viewed as effective. As Chan's studies concerned paper dictionaries only, some modifications were made due to the special features of online dictionaries. Extra column and code/abbreviation were deleted in the entry information as there were no such parts in an online dictionary, while thesaurus and menu were added. The participants had to fill in both introspective and retrospective questionnaires. All the questionnaires were given in English and the participants responded in English. Though the chosen participants are lower intermediate, they are students with English as major subject. Using English to express themselves is one basic requirement in China, and all of them claimed that they could answer the questionnaires in English in spite of some grammatical errors found in their answers.

\subsection{The Macmillan English Dictionary Online}

The Macmillan English Dictionary Online (MEDO) was chosen because it only provides an online version nowadays, and it can be viewed as a leading online 
dictionary. MEDO claims in http://www.macmillandictionary.com/about.html that it is 'the perfect free online dictionary - a one-stop reference for English speakers around the world and is the smart choice for teachers and students, and makes learning, using and understanding English a lot easier!' This statement indicates that MEDO should be useful to advanced learners as well as learners with a lower proficiency. The special thesaurus feature in MEDO is unique among the online dictionaries. The introduction of MEDO reads 'MacmillanDictionary.com contains a thesaurus with a difference. Many online thesauruses sit completely independently from a dictionary and generate an unsystematic and often overwhelming list from the word you have looked up. Faced with this list, it is often difficult to know which synonym to choose, and many words in the list might not relate to the meaning of the word you have searched. The free online thesaurus from Macmillan thesaurus is fully integrated into the dictionary entries, giving you a targeted list of synonyms and words related exactly to the meaning you are looking for.' (http://www. macmillandictionary.com/about_thesaurus.html)

\section{Method}

Thirty-two participants were gathered in a computer lab to do the whole task. In the first part, 10 sentences containing 10 target verb phrases respectively were provided. The participants had to decide on the most appropriate meaning without consulting anything. Their answers were collected before they moved to the second part. To begin the second part, every participant had access to the webpage of www.macmillandictionary.com. Some guidance on how to use MEDO was provided: the verb phrase eat up was given to the participants as a sample. The researcher explained all the parts of this entry, especially the function of the thesaurus. As there is no menu box information under the entry phrase eat up, the single word eat was searched to illustrate the function of the menu to the participants. Participants were then given five extra minutes to practise how to use MEDO. Finally, the same sentences with the same verb phrases underlined and the same meaning options were given. Participants had to do the same task again but with the help of the online dictionary consultation. At the same time, they were required to do the introspective questionnaire immediately after finishing each question. After collecting all the introspective questionnaires and answers of Part Two, a retrospective questionnaire was handed out. Participants were allowed to leave with a gift after they handed in their retrospective questionnaires.

\section{Results}

\subsection{Participants' performance in meaning determination of verb phrases}

To answer the first research question, participants' performance in meaning 
determination of verb phrases was analyzed. Their performance would be measured in terms of accuracy rates.

Without any dictionary consultation, participants' performance was rather poor with an overall accuracy rate of $26.52 \%$. Of the ten verb phrases included in the task, only feed on and run up received an accuracy rate of over $40 \%$. Over half (6) of the phrases received an accuracy rate ranging from $20 \%$ to $30 \%$, and two phrases below $15 \%$. The verb phrase with the lowest accuracy rate was bring forth: only three participants could accurately determine the meaning (Table 1).

Table 1: A comparison between the accuracy rate of each verb phrase with and without the use of MEDO

\begin{tabular}{|c|c|c|}
\hline \multirow{2}{*}{ Verb phrases } & \multicolumn{2}{|c|}{$\begin{array}{l}\text { Percentage of participants who could determine the } \\
\text { meanings of the verb phrases correctly }\end{array}$} \\
\hline & Without MEDO & With MEDO \\
\hline wait on & $28.13 \%(9 / 32)$ & $37.5 \%(12 / 32)$ \\
\hline break down & $12.5 \%(4 / 32)$ & $31.25 \%(10 / 32)$ \\
\hline bring forth & $9.38 \%(3 / 32)$ & $31.25 \%(10 / 32)$ \\
\hline call on & $28.13 \%(9 / 32)$ & $21.88 \%(7 / 32)$ \\
\hline feed on & $46.88 \%(15 / 32)$ & $75 \%(24 / 32)$ \\
\hline fight off & $21.88 \%(7 / 32)$ & $43.75 \%(14 / 32)$ \\
\hline get around & $21.88 \%(7 / 32)$ & $56.25 \%(18 / 32)$ \\
\hline kick in & $28.13 \%(9 / 32)$ & $65.63 \%(21 / 32)$ \\
\hline run up & $43.75 \%(14 / 32)$ & $68.75 \%(22 / 32)$ \\
\hline ring up & $21.88 \%(7 / 32)$ & $65.63 \%(21 / 32)$ \\
\hline Total & $26.25 \%(84 / 320)$ & $49.69 \%(159 / 320)$ \\
\hline
\end{tabular}

After consulting MEDO, participants' performance improved markedly with a total accuracy rate of $49.69 \%$. Half of the phrases (five) received an accuracy rate of over $50 \%$, and the highest one even reached $75 \%$. Four phrases received an accuracy rate ranging from $30 \%$ to $45 \%$. Compared with the previous performance, the participants gained a higher accuracy rate in these nine phrases after consulting MEDO. The verb phrase with the lowest accuracy rate was call on, receiving an accuracy rate of only $21.88 \%$, and it also showed regression from its original rate of $28.13 \%$ (The discussion for this will be presented in Section 6.3). To check whether there was any difference between participants' performance in these two tasks, the results were analyzed through a two-tailed, paired samples $t$-test by using SPSS 21.0. It showed that there was statistically significant difference between the overall meaning determination of the target 
verb phrases before and after the dictionary consultation at the significance level of $0.05(t=-10.522, \mathrm{df}=31, p=0.000)$ (Table 2).

Table 2: A comparison between individual participants' performance in determining the meanings of the verb phrases with and without the use of MEDO

\begin{tabular}{|c|c|c|}
\hline \multirow{2}{*}{ Participants } & \multicolumn{2}{|c|}{ Percentage of meaning determination accuracy } \\
\hline & Without MEDO & With MEDO \\
\hline Participant 1 & $30 \%(3 / 10)$ & $40 \%(4 / 10)$ \\
\hline Participant 2 & $20 \%(2 / 10)$ & $50 \%(5 / 10)$ \\
\hline Participant 3 & $40 \%(4 / 10)$ & $60 \%(6 / 10)$ \\
\hline Participant 4 & $20 \%(2 / 10)$ & $40 \%(4 / 10)$ \\
\hline Participant 5 & $40 \%(4 / 10)$ & $70 \%(7 / 10)$ \\
\hline Participant 6 & $40 \%(4 / 10)$ & $30 \%(3 / 10)$ \\
\hline Participant 7 & $10 \%(1 / 10)$ & $40 \%(4 / 10)$ \\
\hline Participant 8 & $50 \%(5 / 10)$ & $50 \%(5 / 10)$ \\
\hline Participant 9 & $30 \%(3 / 10)$ & $30 \%(3 / 10)$ \\
\hline Participant 10 & $20 \%(2 / 10)$ & $40 \%(4 / 10)$ \\
\hline Participant 11 & $10 \%(1 / 10)$ & $30 \%(3 / 10)$ \\
\hline Participant 12 & $30 \%(3 / 10)$ & $70 \%(7 / 10)$ \\
\hline Participant 13 & $0 \%(0 / 10)$ & $30 \%(3 / 10)$ \\
\hline Participant 14 & $20 \%(2 / 10)$ & $50 \%(5 / 10)$ \\
\hline Participant 15 & $30 \%(3 / 10)$ & $50 \%(5 / 10)$ \\
\hline Participant 16 & $10 \%(1 / 10)$ & $50 \%(5 / 10)$ \\
\hline Participant 17 & $40 \%(4 / 10)$ & $60 \%(6 / 10)$ \\
\hline Participant 18 & $10 \%(1 / 10)$ & $50 \%(5 / 10)$ \\
\hline Participant 19 & $50 \%(5 / 10)$ & $80 \%(8 / 10)$ \\
\hline Participant 20 & $30 \%(3 / 10)$ & $60 \%(6 / 10)$ \\
\hline Participant 21 & $10 \%(1 / 10)$ & $40 \%(4 / 10)$ \\
\hline Participant 22 & $30 \%(3 / 10)$ & $70 \%(7 / 10)$ \\
\hline Participant 23 & $30 \%(3 / 10)$ & $40 \%(4 / 10)$ \\
\hline Participant 24 & $20 \%(2 / 10)$ & $50 \%(5 / 10)$ \\
\hline Participant 25 & $30 \%(3 / 10)$ & $60 \%(6 / 10)$ \\
\hline Participant 26 & $20 \%(2 / 10)$ & $50 \%(5 / 10)$ \\
\hline Participant 27 & $20 \%(2 / 10)$ & $50 \%(5 / 10)$ \\
\hline
\end{tabular}




$\begin{array}{lll}\text { Participant } 28 & 50 \%(5 / 10) & 60 \%(6 / 10) \\ \text { Participant } 29 & 20 \%(2 / 10) & 40 \%(4 / 10) \\ \text { Participant } 30 & 50 \%(5 / 10) & 70 \%(7 / 10) \\ \text { Participant } 31 & 10 \%(1 / 10) & 40 \%(4 / 10) \\ \text { Participant } 32 & 20 \%(2 / 10) & 50 \%(5 / 10) \\ \text { Total } & 26.25 \%(84 / 320) & 49.69 \%(159 / 320)\end{array}$

Based on the results, it can be concluded that MEDO is very useful to Chinese EFL learners to determine the meaning of verb phrases.

\subsection{Perception of usefulness of MEDO}

To answer the second research question, the participants' retrospective questionnaire was explored.

Definitions and examples were the only two which were regarded as extremely or very useful by most participants, receiving $93.76 \%$ and $90.63 \%$ respectively (Table 3 ). These were also the items which most participants consulted, with definitions $75 \%$ and examples $84.38 \%$ (Table 4). Moreover, examples ranked the highest in information from which the answers to most of the questions were found, reaching $87.5 \%$ with 28 participants having chosen them. Definitions just ranked behind examples: $65.63 \%$ participants (21) chose them. Less than one-third (9) of the participants consulted the menu most; only 7 participants could find the answers they needed, and less than half (14) of the participants thought they were useful. Very few consulted the thesaurus, more dictionary definitions, and special features: their percentages were all below $15 \%$. None of the participants used the thesaurus and special features to find the answers to the questions. Fifty percent of the participants considered the thesaurus and special features not very useful, and $40.63 \%$ participants thought that more dictionary information was not very useful. Overall, 18 participants out of 32 deemed MEDO useful; 10 thought the dictionary was very useful; 2 considered it extremely useful; and the other 2 did not view it very useful (Tables 3 and 4).

Table 3: Degree of usefulness of different parts of MEDO

\begin{tabular}{llllll}
\hline Dictionary information & $\begin{array}{l}\text { Extremely } \\
\text { useful }\end{array}$ & $\begin{array}{l}\text { Very } \\
\text { useful }\end{array}$ & Useful & $\begin{array}{l}\text { Not very } \\
\text { useful }\end{array}$ & $\begin{array}{l}\text { Not useful } \\
\text { at all }\end{array}$ \\
\hline Definitions & $28.13 \%$ & $65.63 \%$ & $6.25 \%$ & $0 \%$ & $0 \%$ \\
& $(9 / 32)$ & $(21 / 32)$ & $(2 / 32)$ & $(0 / 32)$ & $(0 / 32)$ \\
Examples & $56.25 \%$ & $34.38 \%$ & $9.38 \%$ & $0 \%$ & $0 \%$ \\
& $(18 / 32)$ & $(11 / 32)$ & $(3 / 32)$ & $(0 / 32)$ & $(0 / 32)$
\end{tabular}




\begin{tabular}{llllll} 
Thesaurus & & & & & \\
& $(0 / 32)$ & $12.5 \%$ & $31.25 \%$ & $50 \%$ & $6.25 \%$ \\
Menu & $(4 / 32)$ & $(10 / 32)$ & $(16 / 32)$ & $(2 / 32)$ \\
& $(0 / 32)$ & $(9 / 32)$ & $(14 / 32)$ & $(4 / 32)$ & $(5 / 32)$ \\
More dictionary & $0 \%$ & $12.5 \%$ & $18.75 \%$ & $40.63 \%$ & $28.13 \%$ \\
definitions & $(0 / 32)$ & $(4 / 32)$ & $(6 / 32)$ & $(13 / 32)$ & $(9 / 32)$ \\
Special features & $0 \%$ & $6.25 \%$ & $28.13 \%$ & $50 \%$ & $15.63 \%$ \\
& $(0 / 32)$ & $(2 / 32)$ & $(9 / 32)$ & $(16 / 32)$ & $(5 / 32)$ \\
Others & $0 \%$ & $0 \%$ & $0 \%$ & $0 \%$ & $0 \%$ \\
& $(0 / 32)$ & $(0 / 32)$ & $(0 / 32)$ & $(0 / 32)$ & $(0 / 32)$ \\
Overall usefulness & $6.25 \%$ & $31.25 \%$ & $56.25 \%$ & $6.25 \%$ & $0 \%$ \\
& $(2 / 32)$ & $(10 / 32)$ & $(18 / 32)$ & $(2 / 32)$ & $(0 / 32)$ \\
\hline
\end{tabular}

Table 4: Perception of the usefulness of different parts of MEDO

\begin{tabular}{lll}
\hline Dictionary information & $\begin{array}{l}\text { Information which partici- } \\
\text { pants consulted most }\end{array}$ & $\begin{array}{l}\text { Information which partici- } \\
\text { pants found the answers to } \\
\text { most of the questions }\end{array}$ \\
\hline Definitions & $75 \%(24 / 32)$ & $65.63 \%(21 / 32)$ \\
Examples & $84.38 \%(27 / 32)$ & $87.5 \%(28 / 32)$ \\
Thesaurus & $6.25 \%(2 / 32)$ & $0 \%(0 / 32)$ \\
Menu & $28.13 \%(9 / 32)$ & $21.88 \%(7 / 32)$ \\
More dictionary definition & $12.5 \%(4 / 32)$ & $6.25 \%(2 / 32)$ \\
Special features & $3.13 \%(1 / 32)$ & $0 \%(0 / 32)$ \\
Others & $0 \%(0 / 32)$ & $0 \%(0 / 32)$ \\
\hline
\end{tabular}

It can be deduced from the results that Chinese EFL learners perceive MEDO as useful in general.

\subsection{Problems encountered in dictionary consultation}

Although MEDO consultation resulted in significant improvements in meaning determination of the verb phrases, all the participants encountered certain difficulties which rendered their false judgments, as no one achieved $100 \%$ accuracy rate after consulting the dictionary. In order to answer the third research question, the participants' introspective questionnaire was scrutinized.

Deficient definitions in the dictionary. As for the phrase wait on, 16 participants chose 'sure that I didn't get the right information', and 13 participants chose 'not sure whether my decision was correct' on ending the dictionary search. Most of them claimed they just couldn't find the answer to the question; the definitions provided in MEDO were not what they need. It might be argued 
that butler is quite a rare word and distracts participants' choice, but this was designed on purpose. If the participants had known that butler means the most important male servant in a wealthy house, they would have guessed the meaning of wait on without consultation.

I only get two meanings, but they are not right to my feeling. One meaning is 'to serve people in a restaurant'. I know this is not the answer, but I feel it's better than the other one, so I guess choice B, because B is close to this one. (Participant 2)

I can't find my answers in the dictionary, so I look for butler. After I know the meaning, I just choose B. But I'm not sure. (Participant 10)

The situation with the phrase bring forth was quite different. Twenty-three participants chose 'sure that my decision was correct' after consulting the dictionary, but only 10 chose the right answer. It could be attributed to the single definition provided in the dictionary. The sole definition 'to produce something, or to cause a particular reaction' is very close to the given option $C$ 'produced something, make it known or visible'. Some participants just attempted to match the key words given in the definition with those provided in the answers. Some participants doubted option $C$, but they still chose it for they believed in the dictionary's authority.

$C$ is a little strange, but the dictionary only provides this definition. I think dictionary should be correct, so I choose $C$. (Participant 7)

I only get one meaning; it is the same with $C$. Then $A, B, D$ must be incorrect. (Participant 11)

Inadequate examples in the dictionary. The accuracy rate of fight off showed significant gains after the dictionary consultation, and 13 participants were sure they did not get the right information. Two definitions were provided in MEDO: while one definition has one example, the other one has no example at all. Some participants complained that one example was far from adequate to help them obtain the right information, and more examples should be provided. Though some of them knew 'to stop someone who is trying to attack you' was the definition they needed, but they had difficulty in differentiating the subtle differences between the options $B$ and $D$. If more examples were provided, they might be able to figure out the right answer. More often than not, definitions together with examples could help them gain a better understanding, and some viewed examples as an essential part during the dictionary consultation.

I like to read examples to help me, but there is only one here. So I choose $B$ according to the context. (Participant 10)

I know the first meaning is the right one, but I still don't know which one to choose. There is only one example under this meaning; I think it should have more examples. (Participant 14) 
Examples are very important, but almost every meaning has only one example, I don't know how to choose: $B$ or $D$ ? (Participant 29)

Unable to distinguish meanings by learners. Call on is the one which received the lowest accuracy rate even with the help of the dictionary. Only 7 participants made the correct judgment. Though 11 participants were sure about their answers, more than half (17) of the participants were sure they did not get the right information. Surprisingly, call on is the only phrase which showed a decreased accuracy rate after the dictionary consultation. The reason might be ascribed to the participants' inability to judge which definition was relevant to the context of the given sentence. Some were daunted by the numerous definitions in the entry and felt confused about their choices. Most of them complained that they could not distinguish so many definitions, especially when this phrase impeded the understanding of the whole sentence. Though definitions were different from one another, participants still found difficulty in seeking the needed information.

There are so many different meanings which make me confused. I don't know how to choose. (Participant 3)

There are five meanings in the dictionary; I just don't know which one is right. (Participant 7)

I am not sure about the meaning of this phrase; there are so many meanings here. (Participant 12)

Preoccupied by the familiar meaning. Results of the phrase break down showed that 21 participants were quite sure they supplied the right answer. But in fact, only 10 participants made the right judgment. Participants' preconception of this phrase might mislead them into selecting an incorrect answer. The preoccupied meaning of this phrase to most participants was 'separate something into parts', probably because 'their opposition' could be separated into parts which could be inferred as shattered or stopped. Most participants chose option $A$ without further consideration, and they paid no attention to the rest of the definitions and examples. If they looked closer at the sixth definition's example 'The aim of the agreement is to break down barriers to trade.', they could find that this example had the same sentence pattern 'break down something to something or somebody' as the given sentence.

There are so many meanings here, but when I see 'separate something into parts', I feel this is the answer. After I put this meaning into the sentence, I can understand the sentence. (Participant 27)

Ignorance of immediate cross-reference. Feed on is the one which showed the highest accuracy rate. Two definitions were provided in the dictionary entry, though one example was provided in the second one, dictionary users have to 
cross reference feed off to get its definition. It means participants have to click on the hyperlink of feed off. The screenshot is shown below.

Figure 1: Entry for feed on in MEDO

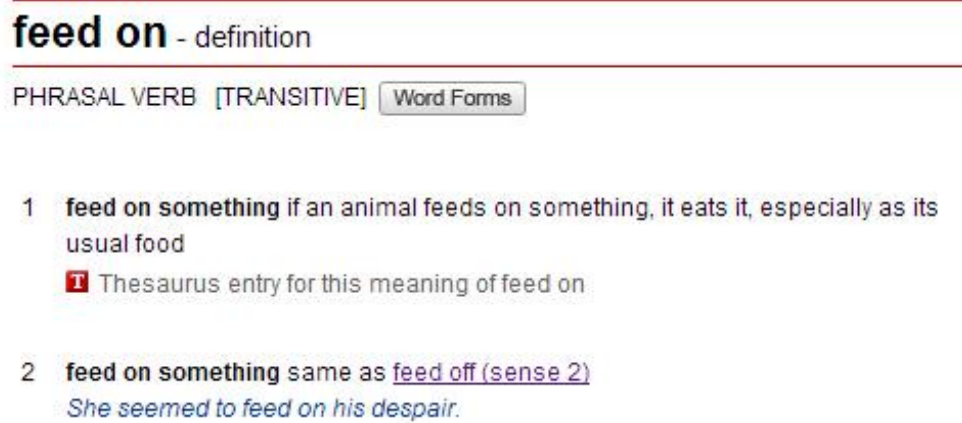

Once participants clicked on feed off, they would get the exact definition as was shown in option $C$. Twenty-four participants made the right judgment, but still 8 participants missed it. Their questionnaires were examined, and some problems were identified. The main problem was due to their ignorance of the hyperlink. It was quite common for most participants to use the hyperlink, but not everyone was familiar with it.

I click feed off, then I got 'to use something in order to continue to exist or become stronger'. I compared the two meanings; I feel 'become stronger' is the one I need. (Participant 18)

I doubt my answer, because there is no definition. (Participant 6)

I cannot find what I want, I just guess. (Participant 31)

To recapitulate, the participants encountered at least four problems. First, they found that they could not find sufficient definitions of certain phrases which hindered their judgements. Secondly, faced with numerous definitions in certain entries, they could not distinguish between them. Thirdly, while some participants complained that no dictionary example or inadequate examples resulted in their false judgements, some were preoccupied by the familiar meaning of a target phrase. Lastly, not every participant knew the function of a hyperlink in an online dictionary.

\section{Discussion and Implications}

Based on this study, it can be argued that the online dictionary is, to some extent, useful in helping Chinese EFL learners to determine the meanings of verb phrases, for there is a significant difference between learners' performance 
before and after the dictionary consultation. However, despite the general usefulness of the online dictionary, no one achieved 100\% accuracy rate. Participants still encountered several problems during the consultation.

An online dictionary is flexible and dynamic; it can offer a layered, hierarchical inner access structure (Dziemianko 2012: 321). Take MEDO for example: if the learner selects a particular sense from the menu which is displayed at the top of the entry, direct access to a specific definition will be provided (Lew and Tokarek 2010). The menu box has the same function, but it only appears under single words with provision of related dictionary definitions. The thesaurus is a special feature of MEDO, but no participant could identify the meaning of this word before it had been explained to them, and participants were unfamiliar with its function. Even though some guidance on how to use the menu and thesaurus was provided, many participants still made use of definitions and examples in the entry most to guide their meaning determination, very rare for the rest part of entry information. One reason for the rare usage of the menu and thesaurus is that learners are quite unfamiliar with these functions, and they are still quite used to the way of using a paper dictionary. Another reason is concerned with the design of the task. Since the task is to determine the appropriate meanings of verb phrases, participants would definitely focus more on definitions. Checking examples at the same time also helps them gain a better understanding and assists them in differentiating semantic differences. If the task is designed in a different way, the result will probably be different.

Participants' perception of the online dictionary may be affected by their language proficiency and their dictionary skills. The participants are all lower intermediates in this study. Compared to advanced learners, they have more difficulty in identifying the correct definition to the corresponding sentences due to their language proficiency. In addition, their preconception of the verb phrases may affect their judgments to a large degree. With no critical thinking or ignorance of other information parts, they usually made an inappropriate decision by guessing or just by matching the definition with the given options when they encountered the situation of finding no relevant answer in the entry's definitions. As for their dictionary skills, there is often a gap 'between the sophistication of the typical dictionary structure and the inadequacy of the reference skills possessed by the average dictionary users' (Lew and Galas 2008: 1273). Despite the gap, learners' dictionary skills are taken for granted. We had assumed that every participant would probably click on the hyperlink of feed off when they looked up feed on. But the factual situation was that not everyone acquired this simple skill. It is quite common in China that dictionary skills are seldom taught, and some teachers may lack adequate skills themselves, especially online dictionary consultation skills.

In general, an online dictionary has many advantages, such as simplified outer access structure, hierarchical inner access structure, clear and concise layout, and eye-catching special features. But to Chinese EFL learners, the inadequacy of definitions and examples are main problems they have encountered. 
Of the ten verb phrases given in the task, only one definition under the entry get around has two examples. Most of the definitions have only one example, and three have no example at all. Several definitions can be found under entry bring forth in other dictionaries, but only one is provided in MEDO. It is a paradox as sometimes learners complain that there are so many definitions and examples which confuse them, whereas sometimes definitions and examples are just inadequate to their use. It is not an easy task to provide enough information without redundancy.

This study has some pedagogical and lexicographic implications. Firstly, dictionary skills should be taught to EFL learners as they are of vital importance. Müller-Spitzer et al. (2012) did a survey on what users expect of online dictionaries. Almost identical to that study, the present study found that online dictionary content received the highest ratings while features typical of online dictionaries received the lowest. As can be found in this study, not every learner possesses adequate skills. Learners have to learn how to make good use of the other information parts of an online dictionary in addition to the definitions and examples. If learners can take advantage of these features and functions, they will be more likely to choose the appropriate answer of the phrases they look up. Secondly, it is important to consider contextual clues during dictionary consultation. Faced with a list of definitions under a certain phrase, it is one of the best ways for learners to resort to the context information to select the appropriate meaning. Training learners to exploit contextual clues may help them reduce their uncertainty of the multiple definitions and increase their accuracy rate. Finally, it should be recognized that learners' success of dictionary look-up may also depend on the dictionary itself. One example provided under a definition is succinct in dictionary's layout to learners, but it may not convey sufficient information which may result in learners' inability to differentiate definitions. Lexicographers should find a solution to this problem and they have to take special care of those entries which provide deficient definition.

\section{Conclusion}

This article reported on the results of a meaning determination task requiring the participants to determine the appropriate meaning of polysemous verb phrases in given sentences with the use of MEDO. Although MEDO is useful for facilitating meaning determination in general, learners still encountered several problems during their consultation. It is suggested that online dictionary skills should be taught to the Chinese EFL learners, and the entry structure and information of an online dictionary should be improved.

\section{Acknowledgements}

This study was funded by the National Social Science Foundation of China (No. 15BYY062), by the MOE Project of Key Research Institute of Humanities 
and Social Sciences at Universities in P.R. China (No. 12JJD740010), and by the Research Project of Humanities and Social Sciences at Universities in Guangdong Province (No. 2012WYXM-0057). We are grateful to Dr. Alice Y.W. Chan of City University of Hong Kong for generously sending us her questionnaires, and to two anonymous adjudicators and Prof. Elsabe Taljard for their insightful comments and valuable suggestions. We would also like to thank all the students for their participation in this study.

\section{References}

Chan, A.Y.W. 2005. Tactics Employed and Problems Encountered by University English Majors in Hong Kong in Using a Dictionary. Applied Language Learning 15(1-2): 1-27.

Chan, A.Y.W. 2012. The Use of a Monolingual Dictionary for Meaning Determination by Advanced Cantonese ESL Learners in Hong Kong. Applied Linguistics 33(2): 115-140.

Chan, A.Y.W. 2013. Advanced Cantonese ESL Learners' Use of a Monolingual Dictionary for Language Production. Lexikos 22: 109-138.

Chen, Y. 2010. Dictionary Use and EFL Learning. A Contrastive Study of Pocket Electronic Dictionaries and Paper Dictionaries. International Journal of Lexicography 23(3): 275-306.

De Schryver, G.-M. 2003. Lexicographers' Dreams in the Electronic-Dictionary Age. International Journal of Lexicography 16(2): 143-199.

Dziemianko, A. 2010. Paper or Electronic? The Role of Dictionary Form in Language Reception, Production and the Retention of Meaning and Collocations. International Journal of Lexicography 23(3): 257-273.

Dziemianko, A. 2012. On the Use (fulness) of Paper and Electronic Dictionaries. Granger, S. and M. Paquot (Eds.). 2012: 319-341.

Granger, S. and M. Paquot (Eds.). 2012. Electronic Lexicography. Oxford: Oxford University Press.

Howarth, P. 1996. Phraseology in English Academic Writing: Some Implications for Language Learning and Dictionary Making. Tübingen: Max Niemeyer.

Hulstijn, J.H. and B. Laufer. 2001. Some Empirical Evidence for the Involvement Load Hypothesis in Vocabulary Acquisition. Language Learning 51(3): 539-558.

Kobayashi, C. 2007. Comparing Electronic and Printed Dictionaries: Their Effects on Lexical Processing Strategy Use, Word Retention, and Reading Comprehension. Bradford-Watts, K. (Ed.). 2007. JALT2006 Conference Proceedings: 657-671. Tokyo: JALT.

Komuro, Y., S. Uchida and Y. Shitara-Matsuo. 2006. An Analysis of the Oxford Advanced Learner's Dictionary Current English, with Special Reference to the CD-ROM. Lexicon 36: 55-146.

Koyama, T. and O. Takeuchi. 2007. Does Look-up Frequency Help Reading Comprehension of EFL Learners? Two Empirical Studies of Electronic Dictionaries. Calico Journal 25(1): 110-125.

Laufer, B. and M. Hill. 2000. What Lexical Information Do L2 Learners Select in a CALL Dictionary and How Does it Affect Word Retention. Language Learning and Technology 3(2): 58-76.

Lew, R. 2012. How Can We Make Electronic Dictionaries More Effective. Granger, S. and M. Paquot (Eds.). 2012: 343-361.

Lew, R. and G.-M. de Schryver. 2014. Dictionary Users in the Digital Revolution. International Journal of Lexicography 27(4): 341-359.

Lew, R. and K. Galas. 2008. Can Dictionary Skills Be Taught? The Effectiveness of Lexicographic 
Training for Primary-School-Level Polish Learners of English. Bernal, E. and J. DeCesaris (Eds.). 2008. Proceedings of the XIII EURALEX International Congress, Barcelona, 15-19 July 2008: 1273-1285. Barcelona: Universitat Pompeu Fabra.

Lew, R. and P. Tokarek. 2010. Entry Menus in Bilingual Electronic Dictionaries. Granger, S. and M. Paquot (Eds.). 2010. eLexicography in the 21st Century: New Challenges, New Applications: 193-202. Louvain-la-Neuve: Cahiers du CENTAL.

Li, L. 2005. The Growing Prosperity of On-line Dictionaries. English Today 21(3): 16-21.

Muller-Spitzer, C., A. Koplenig and A. Töpel. 2012. Online Dictionary Use: Key Findings from an Empirical Research Project. Granger, S. and M. Paquot (Eds.). 2012: 425-457.

Nesi, H. 2000a. Electronic Dictionaries in Second Language Vocabulary Comprehension and Acquisition: The State of the Art. Heid, U., S. Evert, E. Lehmann and C. Rohrer (Eds.). 2000. Proceedings of the Ninth EURALEX International Congress, EURALEX 2000, Stuttgart, Germany, August 8th-12th, 2000. Vol.2: 839-847. Stuttgart, Germany: Institut für Maschinelle Sprachverarbeitung, Universität Stuttgart.

Nesi, H. 2000b. On Screen or in Print? Students' Use of a Learner's Dictionary on CD-ROM and in Book Form. Howarth, P. and R. Herington (Eds.). 2000. EAP Learning Technologies. BALEAP Conference Proceedings: 106-114. Leeds: Leeds University Press.

Nesselhauf, N. 2005. Collocations in a Learner Corpus. Amsterdam/Philadelphia: John Benjamins.

Osaki, S., N. Ochiai, T. Iso, and K. Aizawa. 2003. Electronic Dictionary vs. Printed Dictionary: Accessing the Appropriate Meaning, Reading Comprehension, and Retention. Murata, M., S. Yamada and Y. Tono (Eds.). 2003. Dictionaries and Language Learning: How can Dictionaries Help Human and Machine Learning: Papers submitted to the Third ASIALEX Biennial International Conference, Meikai University, Uruyasu, Chiba, Japan, August 27-29, 2003: 205-212. Tokyo: Asian Association for Lexicography.

Wray, A. 2002. Formulaic Sequences and the Lexicon. Cambridge: Cambridge University Press.

Wray, A. and M.R. Perkins. 2000. The Functions of Formulaic Language: An Integrated Model. Language and Communication 20(1): 1-28. 
Appendix 1: Meaning identification task sheet

Please determine the most appropriate meaning of the underlined verb phrases.

Name: $\quad$ Number: $\quad$ Score:

1. He has a butler who waits on him.

A. waits for a result before being able to make a decision

B. provides someone with everything they need or want

C. stays somewhere after other people have left

D. stays at home because someone is going to visit

2. He had to break down their opposition to his ideas.
A. separate into parts
B. stop working
C. remove a barrier or obstacle
D. end negotiations unsuccessfully

3. The report has brought forth a lot of criticism of the policy.

A. made something happen earlier than originally planned

B. removed something from where it is kept or hidden

C. produced something, make it known or visible

D. made something happen

4. He called the speaker on several mis-statements of fact.

A. ordered someone to stop attacking

B. asked someone to do something, especially to speak in public.

C. made something happen

D. challenged

5. The opposition party is feeding on the government's weaknesses.
A. consuming in an animal's diet
B. giving someone a particular food
C. growing stronger
D. using something to your advantage

6. The old lady managed to fight the muggers off and they didn't get her purse.

A. resist an illness or emotion

B. fight an attacker and force him or her back

C. struggle to see who wins, both by arguing or fighting

D. hit or kick someone who is attacking you 
7. It'll be tricky, but we will find a way to get around the regulations.
A. become known
B. persuade, convince
C. avoid a problem
D. finally manage to do something, make the effort to do something

8. The budget cuts are starting to kick in and people are struggling.
A. pay someone illegally as part of the price
B. contribute money
C. start having an effect
D. cause trouble or pain

\section{He ran up a few examples for them to look at.}
A. encountered problems, often unexpected
B. moved quickly to where someone is
C. did or made something very quickly
D. explained quickly

10. They rang up the bill for the groceries.
A. entered figures into a till or cash register
B. achieved an amount or number
C. made a sudden loud sound
D. charged excessively or obtained money unfairly 